\title{
La caída del Angelus novus: más allá de la ecuación moderna entre raíces y opciones ${ }^{1}$
}

\author{
BOAVENTURA DE SOUSA SANTOS
}

Resumen: A partir de una detenida revisión y discusión de las célebres "Tesis sobre la filosofia de la historia" de Walter Benjamin, el autor de este ensayo intenta reproblematizar la disy untiva sobre la cual se construyen las identidades y los modos de transformación de la modernidad occidental, la alternativa de "raices" y "opciones", reproblematización orientada a explicarnos el singular "momento de transicion" que actualmente vivimos.

\begin{abstract}
On the basis of a detailed review and discussion of Walter Benjamin's "Theses on the Philosophy of History", the author of this essay attempts to reformulate the dilemma on which identities are constructed and the ways in which Western society is transformed, the alternative of "roots" and "equations," a reformulation aimed at explaining the unusual "moment of transition" we are currently experiencing.
\end{abstract}

Palabras clave: modernidad, conflicto social, historia presente, tradiciones críticas.

Key xords: modernity, social conflict, present history, critical traditions.

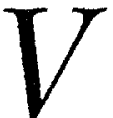

IVIMOS EN UNA ÉPOCA SIN FULGURACIONES, una época de repetición. El grado de veracidad de la teoría sobre el fin de la historia radica en que ésta es el nivel máximo posible de la conciencia de una burguesía internacional que por fin observa el tiempo transformado en la repetición automática e infinita de su dominio. Así, el largo plazo se paraliza en el corto plazo y éste, que siempre fue la moldura temporal del capitalismo, permite a la burguesía producir la única teoría de la historia verdaderamente burguesa: la teoría del fin de la historia. La falta de credibilidad total de dicha teoría no interfiere en nada con el evento de ser en sí una ideología espontánea de los vencedores. El otro lado del fin de la historia es el slogan de la celebración del presente, tan querida en las versiones apocalípticas del pensamiento postmoderno.

La idea de la repetición se refiere a que permite al presente extenderse al pasado y al futuro, como una forma de canibalismo. ¿Nos encontramos frente a una nueva situación? Hasta ahora, la burguesía no ha podido elaborar una teoría de la historia que siga exclusivamente sus propios intereses. Siempre está luchando con fuertes adversarios; primero, las clases dominantes del antiguo régimen y, después, las clases trabajadoras. El desenlace de tal lucha se encontraba siempre en el futuro, el cual,

\footnotetext{
${ }^{1}$ Se trata de una versión revisada y traducida de la ponencia presentada en la Conference on New Approaches to Intemational Law, organizada por la Harvard Law School y por la Universidad de Wisconsin en Madison, llevada a cabo en Madison, Wisconsin, del 14 al 16 de junio de 1996.

* Dirigir correspondencia al Centro de Estudos Sociais. Apartado 3087, 3000, Coimbra, Portugal. Tel: 351-39-826-459 y 351-39-837-328. Fax: 351-39-829-076. E-mail: BSANTOS@gemini.ci.uc.pt.
} 
por la misma razón, no podía ser visto como una mera repetición del pasado. Los nombres asignados a este movimiento orientado al futuro fueron diversos: revolución, progeso, evolución. La revolución puede ser burguesa o proletaria, y al no determinar con anticipación el desenlace de su lucha, puede observar el progreso como la consagración del capitalismo o su superación; el evolucionismo puede ser reivindicado tanto por Herbert Spencer como por Marx. Comunes a las diversas teorías de la historia fueron la desvalorización del pasado y las hipóstasis del futuro. El pasado fue visto como pasado y, por ello, incapaz de hacer su aparición, de irrumpir en el presente. Por el contrario, el poder de revelación y fulguración se trasladó al futuro.

Dentro de este cuadro, la transformación social, la racionalización de la vida individual y colectiva, así como la emancipación social, comenzaron a formar parte del pensamiento. En la medida en que fue construyéndose la victoria de la burguesía, el espacio del presente como repetición se fue ampliando, si bien tal ampliación nunca alcanzó la idea de futuro entendido como progreso. A partir de la crisis de la idea de revolución en la década de los años veinte, se refuerza el reformismo como modelo de transformación social y emancipación, modelo asentado en la coexistencia de la repetición y de la mejoría cuya forma política más acabada se convirtió en el Estado benefactor.

En la actualidad, la dificultad reconocida por nosostros de pensar en la transformación social y la emancipación reside en el colapso de la teoría de la historia que nos ha transportado hasta este momento, provocado por la erosión total de los supuestos que le confirieron credibilidad en el pasado. Como mencioné, la burguesía siente que su victoria histórica se ha consumado y el vencedor consumado sólo está interesado en la repetición del presente; el futuro como progreso puede, en realidad, significar una amenaza peligrosa. En estas condiciones, paradójicamente, la conciencia más conservadora es la que intenta rescatar el pensamiento del progreso, pero sólo porque se resiste a aceptar que la victoria se haya consumado. Para lograrlo, construye enemigos externos, tan poderosos como incomprensibles, una especie de ancien régime externo. Tal es el caso de Samuel Huntingon (1993) y la amenaza que ve en las civilizaciones no occidentales, en especial la del Islam.

Por el otro lado, los grandes vencidos de este proceso histórico, los trabajadores y los pueblos del Tercer Mundo, tampoco son de interés para el futuro en cuanto progreso, toda vez que fue en su seno donde se generó su propia derrota. Incluso en la versión más tenue del futuro, el modelo de repetición/mejoría característico del reformismo - que aun así sólo se hizo posible para una pequeña fracción de vencidos en el llamado "mundo desarrollado"- aparece en la actualidad, si bien es deseado, como insustentable, en virtud de la fatalidad con que se propaga el desmoronamiento del Estado benefactor. Si la repetición del presente es intolerable, más lo es la perspectiva de su abandono. De repente aparece la repetición y el empeoramiento como el menor de los males.

Pero si, por un lado, el futuro parece vacío y sin sentido, por el otro, el pasado es tan intransferible como siempre. La capacidad de resplandor, de irrupción, explosión, revelación, en suma, la capacidad mesiánica, como diría Walter Benjamin (1980:694), 
fue trasladada al futuro por la modernidad occidental. La inutilización del futuro no abre espacios para utilizar el pasado. Llana y simplemente dejamos de observar el pasado de modo utilizable.

En mi opinión, no podemos pensar en la transformación social y la emancipación si no reinventamos el pasado. Lo que propongo en este texto es el fragmento de una nueva teoría de la historia que nos permita volver a pensar en la emancipación social a partir del pasado y, de algún modo, de cara al futuro.

\section{LA PARÁBOLA DEL ANGELUS NOVUS}

Comienzo con la alegoría de la historia de Walter Benjamin. Dice así:

Hay un cuadro de Klee llamado Angelus novus. Representa un ángel que parece estar alejado de algo que mira fijamente. Sus ojos están muy abiertos, la boca abierta y las alas extendidas. Es, sin duda, el aspecto del ángel de la historia. Vuelve el rostro hacia el pasado. Donde vemos frente a nosotros una cadena de acontecimientos, él observa una catástrofe perenne que amontona sin cesar ruinas sobre ruinas y las va arrojando a sus pies. De seguro le gustaría quedarse ahí, despertar a los muertos y volver a unir lo que fue destrozado. Sin embargo, una tempestad sale del paraíso que le levanta las alas y es tan fuerte que el ángel no puede cerrarlas. La tempestad lo arrastra al futuro irremediablemente, al que le ha dado la espalda, mientras que el montón de ruinas frente a sí va creciendo hasta llegar al cielo. La tempestad es lo que llamamos "progreso" (Benjamin, 1980:697-698).

$\mathrm{El}$ ángel de la historia contempla, impotente, la acumulación de ruinas y de sufrimiento a sus pies. Le gustaría quedarse, echar raíces en la catástrofe para, a partir de ella, despertar a los muertos y reunir a los vencidos, pero la fuerza de la voluntad impera sobre la fuerza que lo obliga a escoger el futuro, al cual le da la espalda. Su exceso de lucidez se combina con la falta de eficacia. Aquello que conoce bien y que podía transformar se le vuelve algo extraño y, por el contrario, se entrega sin condiciones a lo desconocido. Las raíces no tienen sustento y las alternativas son ciegas. Así, el pasado es un relato y nunca un recurso, una fuerza capaz de irrumpir en un momento de peligro para auxiliar a los vencidos. Lo mismo dice Benjamin en otra tesis sobre la filosofía de la historia: "Articular el pasado históricamente no significa reconocerlo 'como fue en realidad'. Significa apoderarnos de una memoria tal como ella relampaguea en un momento de peligro" (1980:695). La capacidad de redención del pasado radica en la posibilidad de surgir inesperadamente en un momento de peligro, como fuente de inconformismo.

Según dice Benjamin, el inconformismo de los vivos no existe sin el inconformismo de los muertos, ya que "ni éstos estarán a salvo del enemigo, si es éste el vencedor". Y añade, "este enemigo no ha dejado de ganar" (1980:695). Trágico es, pues, el hecho de que el ángel de la historia moderna cobije en el pasado su capacidad de 
explosión y redención. Imposible es el inconformismo de los muertos como imposible el inconformismo de los vivos. ${ }^{2}$

¿Cuáles son las consecuencias de esta tragedia? Al igual que Benjamin, atravesamos un momento de peligro. Y como tal, pienso cuán importante es colocar al ángel de la historia en otra posición, reinventar el pasado a modo de restituirle la capacidad de explosión y redención. La partida parece una tarea imposible en la medida en que, después de siglos de hegemonía de la teoría modernista de la historia, no tenemos otra posición para observar el pasado, sólo la que nos ofrece el ángel. Me atrevo, entonces, a pensar que este fin de siglo nos ofrece una oportunidad para romper con el dilema, oportunidad que radica precisamente en la crisis por la que está atravesando la idea de progreso. La tempestad que sopla del Paraíso sigue sintiéndose, pero con menos intensidad. El ángel continúa en la misma posición, pero la fuerza que lo sustenta va desvaneciéndose. Hasta es posible que la posición sea producto de la inercia y que el ángel de Klee haya dejado de ser un ángel trágico para convertirse en una marioneta en posición de descanso. Es una sospecha la que me permite continuar con este texto. Comenzaré por proponer una narración de la modernidad occidental para, enseguida, presentar el prefacio de otra narración.

\section{RAÍCES Y OPCIONES}

La construcción social de la identidad y de la transformación en el mundo moderno de Occidente se basa en una ecuación entre raíces y opciones. Esta ecuación confiere al pensamiento moderno un carácter doble: por un lado, pensamiento de raíces, por el otro, pensamiento de alternativas. El pensamiento de las raíces es el pensamiento de todo lo profundo, permanente, único y singular, todo aquello que da seguridad y consistencia; el pensamiento de las opciones es el pensamiento de todo aquello que es variable, efímero, sustituible, posible e indeterminado a partir de las raíces. La diferencia fundamental entre las raíces y las opciones es de escala. Las raíces son entidades de gran escala. Como sucede en la cartografía, cubren vastos territorios simbólicos y largos periodos históricos, pero las características del terreno no permiten levantar cartas topográficas en detalle y sin ambigüedades. Es, pues, un mapa que orienta tanto como desorienta. Por el contrario, las entidades de pequeña escala cubren territorios confinados y periodos cortos, pero lo hacen con el suficiente detalle como para permitir calcular el riesgo de selección entre opciones y alternativas. Tal diferencia de escala permite que las raíces sean únicas y la selección, múltiple, y que, a pesar de ello, la ecuación entre ellas sea viable, sin llegar a ser trivial. La dualidad de las raíces y opciones es una dualidad fundadora y constituyente, es decir, no está sometida al juego que se establece entre raíces y opciones. En otras

\footnotetext{
${ }^{2}$ Un análisis reciente de la teoría de la historia de Walter Benjamin puede leerse en Ribeiro (1995). Cf. también Comesaña (1993).
} 
palabras, no existe la opción si no se piensa en términos de raíces y opciones. La eficacia de esta ecuación se asienta en una doble estratagema. En primer lugar, la estratagema del equilibrio entre el pasado y el futuro. El pensamiento de las raíces se presenta como un pensamiento del pasado en contraposición con el pensamiento de las opciones, el pensamiento del futuro. Se trata de una estratagema porque, de hecho, tanto el pensamiento de las raíces como el de las opciones son pensamientos del futuro, orientados al futuro. El pasado, en esta ecuación, es tan sólo una manera específica de construir el futuro.

La segunda estratagema es la del equilibrio entre raíces y opciones. La ecuación se presenta como simetría, como un equilibro entre raíces y alternativas, y como un equilibrio en la distribución de opciones. Pero, de hecho, no es así. Por un lado, el predominio de las opciones es total. Es una realidad que en ciertos momentos de la historia, o desde ciertos grupos sociales, se atribuye predominancia a las raíces, mientras que en otros se atribuye a las opciones. Resulta un juego o movimiento de raíces a opciones y de opciones a raices en el que predomina uno de los vectores en la narración de la identidad y la transformación. Pero siempre se trata de opciones. Mientras que ciertos tipos de opciones presuponen el predominio discursivo de las raíces, otros le otorgan un papel secundario. El equilibro es intangible. Según el momento histórico o el grupo social, la raíces predominan sobre las opciones o, por el contrario, las opciones predominan sobre la raíces. El juego es siempre de las raíces a las opciones y de las opciones a las raíces; sólo varía la fuerza de los dos vectores como narración de identidad y transformación. Por otro lado, no existe equilibrio o equidad en la distribución social de las opciones. Por el contrario, las raíces no son más que constelaciones de determinantes que, al definirse en el campo de las opciones, definen también a los grupos sociales que pueden tener acceso a ellas y a los que están excluidos.

Algunos ejemplos ayudarán a concretar este proceso histórico. Es a la luz de la ecuación de raices y opciones que la sociedad occidental moderna ve a la sociedad medieval y se distingue de ella. La sociedad medieval es vista como una en la cual las raíces predominan totalmente, sean éstas la religión, la teología o la tradición. La sociedad medieval no es necesariamente estática; evolucionó siguiendo una lógica de raíces. Por el contrario, la sociedad moderna se ve como una sociedad dinámica que evoluciona siguiendo una lógica de opciones. La primera señal importante de cambio en la ecuación es, tal vez, la Reforma de Lutero. Con ella se hace posible, a partir de la misma raíz - la Biblia de la cristiandad occidental-, generar una alternativa frente a la iglesia de Roma. La religión, al volverse optativa, pierde intensidad si no es que status, en cuanto raíz. La teorías racionalistas del derecho natural del siglo XVII reconstituyen la ecuación entre raíces y opciones de manera enteramente moderna. La raíz es ahora la ley de la naturaleza por el ejercicio de la razón y la observación. La intensidad de esta raíz está en que se sobrepone a Dios. En De Jure Belli ac Pacis, Grotius, el mejor exponente de la nueva ecuación, afirma: "Lo que hemos llegado a afirmar tendría un grado de validación aun cuando admitiéramos, lo que no puede ser admitido sin la mayor perversidad, que no hay un Dios, o bien, que los asuntos 
del hombre no le preocupan" (1964:11-13). ${ }^{3}$ A partir de esta raíz tan pasmosa, pueden ser posibles las opciones más dispares. Por esta razón, y no por las que invoca, Tuck acierta cuando afirma que el tratado de Grotius "posee el rostro de Jano y sus dos bocas hablan tanto el lenguaje del absolutismo como el lenguaje de la libertad" (1979:79). Esto es lo que pretende Grotius. Sustentado por la raíz de la law of nature, el derecho puede decidir promover la jerarquía (el jus rectorium, como lo llama) o la igualdad (el jus equatorium).

En el mismo proceso histórico en que la religión transita del status de raíz al de opción, la ciencia transita, por el contrario, del status de opción al de raíz. La propuesta de Giambattista Vico de la "nueva ciencia" (1961) se refiere a un marco decisivo en esta transición que dio inicio con Descartes y se consumó en el siglo XIX. La ciencia, al contrario de la religión, es una raíz que nace en el futuro, es una opción que, al radicalizarse, se transforma en raíz y, a partir de entonces, genera un inmenso campo de posibilidades y de imposibilidades, es decir, de opciones.

Este juego de movimien to y de posición entre raíces y opciones alcanza su desarrollo pleno con el Iluminismo. Dentro de un vasto campo cultural — que va de la ciencia a la política, de la religión al arte-, las raíces se asumen claramente como el otro, radicalizado, de las opciones, tanto de las que son posibles como de las que pueden ser imposibles. De esta forma, la razón, transformada en raíz última de la vida individual y colectiva, no tiene otro fundamento que el de generar opciones; aquí es donde la razón se distingue, en cuanto raíz, de las raíces de la sociedad del ancien régime (la religión y la tradición). Se trata de una raíz que, al radicalizarse, abre el campo a enormes opciones.

De cualquier forma, las opciones no son infinitas. Ello es particularmente evidente en la otra gran raíz del Iluminismo: el contrato social y la voluntad general que lo sustenta. El contrato social es la metáfora que origina una opción radical - la de dejar el estado de naturaleza para formar la sociedad civil-que se transforma en una raíz a partir de la cual casi todo es posible, todo excepto volver al estado de naturaleza. La contractualización de las raíces es irreversible, y éste es el límite de reversibilidad de las opciones. La voluntad general, según Rousseau, no puede ser puesta en duda por los hombres libres que genera. En el Contrato social dice: "quien se niegue a obedecer la voluntad general será obligado a ello por todo el cuerpo: lo que apenas significa que será forzado a ser libre" (1989:27).

La contractualización de las raíces es un proceso histórico largo y accidentado. Por ejemplo, el romanticismo es, fundamentalmente, una reacción contra la contractualización de las raíces y la reivindicación de su falta de disponibilidad y de su singularidad. Sin embargo, las raíces románticas están tan orientadas al futuro como las del contrato social. En ambos casos, se intenta abrir un campo de posibilidades que permi-

\footnotetext{
${ }^{3}$ En otro trabajo analizo con más detalle las teorías de Grotius y las teorías racionalistas del derecho natural (Santos, 1995:60-63).
} 
ta distinguir entre las opciones posibles y las imposibles, entre las opciones legítimas y las ilegítimas.

Entonces puede afirmarse que, con el Iluminismo, la ecuación raíces/opciones se convierte en la forma hegemónica de pensar la transformación social y el lugar de los individuos y los grupos sociales en esa transformación. Una de las manifestaciones más elocuentes de este paradigma es el motivo del viaje como metáfora central del modo de estar en el mundo moderno. De los viajes reales de la expansión europea a los viajes reales e imaginarios de Descartes, Montaigne, Montesquieu, Voltaire o Rousseau, el viaje tiene una carga simbólica doble: por un lado, es el símbolo del progreso y enriquecimiento material o cultural; por otro, es el símbolo del peligro, de la inseguridad y de la pérdida. Una faceta doble que hace que el viaje contenga en sí mismo a su contrario, la idea de una posición fija, la casa (oikoso domus) que da sentido al viaje, le confiere un punto de partida y un punto de llegada. Van der Abbeele dice, el oikos "actúa como un punto transcendental de referencia que organiza y domestica una cierta área mediante la definición de todos los demás puntos en relación a sí mismo" (1992:XVIII).

En suma, el oikos es un fragmento del viaje que no viaja, con el fin de lograr que ese viaje tenga sentido. El oikos es la raíz que sustenta y limita las opciones de vida o de conocimiento que el viaje hace posible. A su vez, el viaje refuerza la raíz de origen en la medida en que, por vía del exotismo de los lugares que permite visitar, hace más profunda la familiaridad de la casa de donde se parte. El relativismo cultural que surge de la actitud comparativa de los viajeros imaginarios del Iluminismo tiene como límite la afirmación de la identidad y, en casi todos ellos, otorga superioridad a la cultura europea. De hecho, Montaigne nunca viajó a América, como tampoco lo hicieron Montesquieu a Persia ni Rousseau a Oceanía, pero la realidad es que todos ellos viajaron a Italia en busca de las raíces de la cultura europea, raíces veneradas mientras más brutal era el contraste con la degración de Italia en la época de esos viajes.

El motivo del viaje es lo que mejor muestra la discriminación y desigualdad que la ecuación moderna raíces/opciones oculta y procura justificar. Por un lado, el viaje a esos lugares exóticos para muchos no fue voluntario ni perseguía profundizar en cierta identidad cultural. Por el contario, se trató de un viaje forzado y su objetivo era destruir la identidad. Esto se refiere sin duda al tráfico de esclavos. Por otro lado, el motivo del viaje es falocéntrico. El viaje presupone, como ya mencioné, la fijeza del punto de partida y de llegada, la casa (el oikos o domus), y la casa es el lugar de la mujer. La mujer no viaja, con lo que hace posible el viaje. Además, esta división sexual del trabajo dentro del motivo del viaje es uno de los topoi más resistentes en la cultura occidental, y tal vez lo es también en otras culturas. La versión arquetípica del viaje en la cultura occidental es La Odisea. La Penélope doméstica se hace cargo de la casa mientras Ulises viaja. La larga espera de Penélope es la metáfora de la solidez del punto de partida y de llegada que garantiza la posibilidad y aleatoriedad de las peripecias por las que pasa el viajero Ulises. 
El interés del motivo del viaje en este contexto radica en que, a través de éste, es posible identificar las determinaciones sexistas, racistas y clasistas de la ecuación moderna entre raíces y opciones. El campo de posibilidades que abre la ecuación no es igual para todos. Algunos, quizá la mayoría, son excluidos de este campo. Para ellos, las raíces, lejos de ofrecer nuevas opciones, significan el dispositivo, nuevo o viejo, que se las niega. Las raíces que otorgan opciones a los hombres, a los blancos y a los capitalistas, son las mismas que las niegan a las mujeres, a los negros, a los trabajadores. A finales del siglo XIX se consolida el juego de espejos entre raíces y opciones y se convierte en la idéologie savante de las ciencias sociales. Los dos ejemplos más brillantes son, sin duda, Marx y Freud.

En Marx, la base es la raíz y la superestructura son las opciones. No se trata de una vulgar metáfora como algunos marxistas no vulgares quieren hacer creer. Se trata de un principio lógico de racionalidad social que atraviesa toda la obra de Marx y, de hecho, la de muchos otros científicos sociales que discrepaban. Baste mencionar el caso de Durkheim, para quien la conciencia colectiva es la raíz siempre amenazada en una sociedad que se basa en la división del trabajo social y en las opciones que ésta multiplicạ indefinidamente. El mismo pensamiento está presente en Freud y Jung. La importancia del inconsciente en la psicología de las profundidades radica precisamente en el hecho de que éste es la raiz profunda donde se edifican las opciones del ego o su limitación neurótica. Del mismo modo, en el nivel más amplio del Freud cultural y de Jung, tal como los analiza Peter Homans, "la interpretación distingue la infraestructura inconsciente de la cultura para así liberar el intérprete de los poderes opresivos y coercitivos de ésta" (1993:xx).

El factor común entre la revolución comunista y la revolución introspectiva es que ambas son respuestas creativas a la profunda desorganización social e individual de una sociedad que está experimentando la pérdida de los ideales, símbolos y modos de vida que han constituido su herencia común. La orientación al futuro en la ecuación raíces/opciones está presente tanto en Marx como en Freud. Si para Marx la base es la llave de la transformación social, para Freud o Jung no tiene sentido investigar el inconsciente fuera de un contexto terapéutico. Así, el materialismo histórico y la psicología de las profundidades se proponenen ir a las raíces de la sociedad moderna - del capitalismo y de la cultura occidental, respectivamente- para abrir opciones nuevas y más amplias. El éxito de su teoría, para cualquiera de ellos, radica en que pueda transformarse en fundamento e instrumento de tal transformación.

En un mundo que perdió hace mucho el "pasado profundo", la raíz de la religión, la ciencia es tanto para Marx como para Freud la única raíz capaz de sustentar un nuevo comienzo en la sociedad moderna occidental. A partir de ella, las buenas opciones son las legitimadas científicamente. Ello implica, para Marx, la distinción entre realidad e ideología y, para Freud, la distinción entre realidad y fantasía. En esta distinción reside también la posibilidad de la teoría crítica de la actualidad. Como dijo Nietzsche, si desaparecieran las realidades también desaparecerian las apariencias. Y lo contrario también es cierto. 
La traducción política liberal de esta nueva ecuación entre raíces y opciones es el Estado-nación y el derecho positivo, convertidos en las raíces que crean el inmenso campo de las opciones en el mercado y en la sociedad civil. El derecho, para poder funcionar como raíz, debe ser autónomo, es decir, científico. Esta transformación no se dio sin resistencias. En Alemania, por ejemplo, la escuela histórica recuperó para el derecho la vieja ecuación entre raíces y opciones, el derecho como emancipación del Volksgeist. Pero fue derrotada por la nueva ecuación, la raízjurídica constituida por la codificación y el positivismo. A su vez, el Estado liberal se constituyó como raíz gracias a la imaginación de la nacionalidad homogénea y de la cultura nacional. Por medio de ellas, el Estado se convierte en el guardián de una raíz que no existe más allá de él.

\section{EL FIN DE LA ECUACIÓN}

Estamos por llegar a un momento peligroso, en el sentido que le atribuyó Walter Benjamin. Según mi entender, éste radica en buena medida en el hecho de que la ecuación moderna entre raíces y opciones, con la que aprendemos a pensar la transformación social, está a punto de pasar por un proceso de profunda desestabilización que parece irreversible. Ésta se presenta bajo tres formas principales: turbulencia de las escalas, explosión de raíces y opciones, trivialización de la ecuación entre raíces y opciones.

Un comentario breve sobre cada una de ellas. Por lo que respecta a la turbulencia de las escalas, es importante recordar lo que mencioné con anterioridad sobre la diferencia de escalas entre las raíces (a gran escala) y las opciones (a pequeña escala). La ecuación raíces/opciones se asienta en esa diferencia y en la estabilidad de tal diferencia. En la actualidad vivimos tiempos turbulentos que se manifiestan a través de una confusión caótica de escalas entre fenómenos. La violencia urbana es paradigmática en ese sentido. Cuando un niño de la calle busca abrigo para pasar la noche y por esa misma razón es asesinado por un policía, o cuando una persona es abordada por un mendigo en la calle y al negarse a dar limosna es asesinada por éste, lo que ocurre es una explosión imprevisible en la escala del conflicto: un fenómeno que parece trivial y sin consecuencias se coloca en ecuación con otro dramático y de consecuencia fatales. Este cambio abrupto e imprevisible de la escala de los fenómenos ocurre en la actualidad en los más diversos dominios de la práctica social, por lo que me atrevo a considerarlo como una de las características fundamentales de nuestro tiempo. Según el ejemplo de Prigogine (1979:1980), pienso que nuestras sociedades atraviesan por un periodo de bifurcación. Como es sabido, esta condición se da en sistemas inestables cuando un cambio mínimo puede producir transformaciones cualitativas de modo imprevisible y caótico. Dicha explosión abrupta de escala genera una enorme turbulencia y coloca al sistema en una situación de vulnerabilidad irreversible. 
Pienso que la turbulencia de nuestro tiempo es de tal tipo y en ella reside la enorme vulnerabilidad a que están sujetas las formas de subjetividad y de sociabilidad: del trabajo a la vida sexual, de la ciudadanía al ecosistema. Esta situación de bifurcación repercute en una ecuación raíces/opciones, lo que origina que la diferencia de escala entre raíces y opciones sea caótica y reversible. La inestabilidad política de nuestro tiempo, de los Balcanes a la ex Unión Soviética, del Medio Oriente a África, tiene mucho que ver con transformaciones bruscas en las escalas, tanto de las raíces como de las opciones. Cuando se desmoronó la Unión Soviética, los casi 25 millones de rusos que vivían fuera de Rusia en las diversas repúblicas que conformaban la Unión vieron de repente que su raíz, su identidad nacional, era minimizada y reducida al estatuto de identidad local, propia de una minoría étnica. Por el contrario, los serbios en la ex Yugoslavia procuraron, con el apoyo inicial de los países occidentales, ampliar la escala de sus raíces nacionales hasta llegar al canibalismo de las raíces nacionales de sus vecinos. No son nuevos estos cambios de escala, toda vez que ya ocurrieron en la postguerra con el proceso de descolonización y el surgimiento de nuevos estados postcoloniales, llamados "nacionales". Lo nuevo en estos cambios es precisamente el hecho de que se llevaron a cabo sobre las ruinas de estados que habían reclamado para sí la titularidad de la raíces de identidad.

La misma explosión en apariencia errática de las escalas se da en el campo de las opciones. En el campo de la economía, la fatalidad con que se imponen ciertas opciones, como por ejemplo, los ajustes estructurales y las drásticas consecuencias que éstos producen, hacen que la pequeña escala se amplíe hasta convertirse en una gran escala y que el corto plazo se transforme en una larga duración instantánea. El ajuste estructural para los países del Sur, lejos de ser una opción, es una raíz transnacional que envuelve y asfixia las raíces nacionales y las reduce a protuberancias locales. Por otro lado, el contrato social, la metáfora de la contractualización de las raíces políticas de la modernidad, en la actualidad está sujeto a una gran turbulencia. El contrato social es un contrato-raíz que se basa en la opción, compartida por todos, de abandonar el estado natural. Doscientos años después, el desempleo estructural, el recrudecimiento de las ideologías reaccionarias, el aumento exagerado de las desigualdades socioeconómicas entre los países que componen el sistema mundial y en el interior de cada uno de ellos, el hambre, la miseria y enfermedad a que está sujeta la población de los países del Sur y las poblaciones tercermundistas internas en los países del Norte, todo ello nos hace creer que estamos ante la opción de excluir del contrato social a un fragmento significativo de la población de nuestros países, y obligarlo a que vuelva a su estado natural, convencidos de que sabremos defendernos eficazmente de la agitación que tal expulsión puede causar.

La segunda manifestación de la desestabilización de la ecuación es la explosión simultánea de las raices y las opciones. De hecho, lo que comúnmente se llama "globalización", una articulación de la sociedad de consumo con la sociedad de información, ha dado origen a la multiplicidad infinita, en apariencia, de opciones. El campo de posibilidades se ha expandido enormemente, legitimado por las propias fuerzas que hacen posible tal expansión, sean éstas la tecnología, la economía de mercado, la 
cultura global de la publicidad y el consumismo o la democracia. Si se amplían las opciones, éstas se transforman de manera automătica en un derecho a tal ampliación. Sin embargo, en aparente contradicción con esto, vivimos una época de localismos y territorialidades, de identidades y singularidades, de genealogías y memorias; en suma, una época de multiplicación, otra vez sin límites, de las raíces. Y también en este caso, descubrir raíces una y otra vez, se traduce de inmediato en un derecho a las raíces descubiertas.

La explosión de raíces y opciones no se da sólo por la multiplicación indefinida de unas y otras; surge también por la búsqueda de raíces más profundas y fuertes que sustenten opciones particularmente dramáticas y radicales. El campo de las posibilidades se reduce en este caso de manera drástica, pero las opciones restantes son dramáticas y están cargadas de consecuencias. Los dos ejemplos más elocuentes de esta explosión de raíces y opciones generada por el aumento excesivo de unas y otras son los fundamentalismos y la investigación sobre el ADN. El fundamentalismo liberal, entre todos los fundamentalismos, es, sin duda, el más intenso. Como el marxismo pasa actualmente por una crisis, el capitalismo se volvió marxista. La economía de mercado, el último seudónimo del capitalismo, se transformó, en las últimas décadas, en el nuevo contrato social, en la base o raíz económica universal que empuja a la mayoría de los países hacia opciones dramáticas y radicales y, para muchos de éstos, a elegir entre el caos de la exclusión y el caos de la inclusión. Por otro lado, la investigación sobre el $\mathrm{ADN}$, conducida en el ámbito del proyecto sobre el genoma humano, significa, en términos culturales, la transformación del cuerpo en la última raíz a partir de la cual se abren las opciones dramáticas de la ingeniería genética. El boom de la investigación de las neurociencias sobre el cerebro en los últimos años - la que ya se llama "década del cerebro"- puede interpretarse como otro medio de convertir el cuerpo en la raíz última. Comenzamos el siglo Xx con la revolución socialista y la revolución introspectiva, y estamos por terminarlo con la revolución corporal. El papel central que en su momento asumieron la clase y la psique, en la actualidad to ha asumido el cuerpo, convertido, al igual que la razón iluminista, en la raíz de todas las opciones.

La explosión extensiva e intensiva de raíces y de opciones puede desestabilizar realmente la ecuación entre raíces y opciones sólo en la medida en que se articula con su intercambiabilidad. Vivimos una época de descubrimiento y desconstrucción. Observamos que muchas de las raíces a las que volvimos la mirada eran, al final, opciones disfrazadas. Las teorías y la epistemología feministas, las teorias críticas de la raza, los estudios postcoloniales y la nueva historia significan una contribución decisiva en este campo. De la opción occidental/oriental de la primatología, estudiada por Donna Haraway (1989), a la opción sexista y racista del Estado benefactor analizada por Linda Gordon (1990, 1991); de la opción denunciada por Martin Bernal (1987) de eliminar las raíces africanas de la Black Athena con el fin de intensificar su pureza como raiz de la cultura europea a la opción de blanquear el Black Atlantic para ocultar los sincretismos de la modernidad, como mostró Paul Gilroy (1993), observamos que las raíces de nuestra sociabilidad y racionalidad son, de hecho, optativas, 
dirigidas más bien a una idea hegemónica de futuro que les dio sentido, y no hacia el pasado que, al final, sólo existió para funcionar como espejo anticipado del futuro.

Sin embargo, paradójicamente, este descubrimiento y la denuncia que lleva consigo se trivializan a medida que se profundizan. Porque detrás de la máscara sólo existe otra máscara: el saber que las raíces hegemónicas de la modernidad occidental son opciones disfrazadas otorga a la cultura hegemónica la oportunidad de imponer, ahora sin necesidad de disfraces y con gran arrogancia, sus opciones como raices. El caso más elocuente tal vez sea el The Western Canon, de Harold Bloom (1994). Ahí explica que las raíces son un mero efecto del derecho a las raíces y, éste, un mero efecto del derecho a las opciones. Es cierto que la posibilidad de dicha claridad curbulenta entre raíces y opciones también está abierta a grupos y culturas contrahegemónicos, pero está abierta precisamente en la medida en que refuerza su carácter contrahegemónico.

En la nueva constelación de sentido, raíces y opciones dejan de ser entidades cualitativamente distintas. Ser raíz o ser opción es un efecto de escala y de intensidad. Las raices son la continuación de las opciones en una escala y con una intensidad diferentes y ocurre lo mismo con las opciones. Esta circularidad permite que el derecho a las raíces y el derecho a las opciones sean mutuamente traducibles. Son isomórficos y se formulan en lenguas y discursos diferentes. Todo se transforma en una cuestión de estilo.

El juego de espejos entre raíces y opciones alcanza la exacerbación en el ciberespacio. En Internet, las identidades son doblemente imaginadas: como imaginaciones y como imágenes. Cada quien es libre de crear las raíces que desee y, a partir de ellas, reproducir sus opciones hasta el infinito. Así, la misma imagen puede observarse como una raíz sin opciones o como una opción sin raíces y, en esa medida, pensar en los términos de la ecuación raíces/opciones deja de tener sentido. De hecho, esta ecuación sólo parece tener sentido en una cultura conceptual, logocéntrica que discurre sobre matrices sociales y territoriales (espacio y tiempo) y las somete a criterios de autenticidad. A medida que transitamos hacia una cultura centrada en imágenes, el espacio y el tiempo van siendo sustituidos por los instantes de la velocidad, las matrices sociales van siendo sustituidas por mediatrices y, en el mismo nivel, el discurso de la autenticidad se transforma en una jerga indescifrable. No existe más profunđđidad que la sucesión de imágenes. Todo lo que está por debajo y por detrás, también está por encima y enfrente. En esta tesitura, tal vez el análisis de Gilles Deleuze (1968) sobre el rizoma adquiere una nueva actualidad. En efecto, Mark Taylor y Esa Saarinen, dos filósofos de los medios, afirman que "el registro imaginario transforma las raíces en rizomas. Una cultura rizomática no está ni enraizada ni desenraizada. Nunca sabremos por dónde irán a irrumpir los rizomas" (1994:Gaping 9).

La condición de nuestra condición es que pasamos por un periodo de transición. Las matrices coexisten con las mediatrices; el espacio y el tiempo, con los instantes de velocidad; la inteligibilidad del discurso de la autenticidad, con su inteligibilidad. 
La ecuación entre raíces y opciones ora hace que todo tenga sentido, ora hace que nada tenga sentido. Estamos frente a una situación más compleja que la de Nietzsche porque, en nuestro caso, tanto se acumulan realidades y apariencias como desaparecen unas y otras. Estas oscilaciones drásticas de sentido son, tal vez, la causa última de la trivialización de la ecuación entre raíces y opciones: la tercera manifestación de la desestabilización de esta ecuación en nuestro tiempo.

La trivialización de la distinción entre raíces y opciones implica la trivialización de unas y otras. Aquí reside nuestra dificultad de pensar la transformación social de la actualidad. Es que el pathos de la distinción entre raíces y opciones es inherente al modo moderno de pensar la transformación social. Entre más intenso sea ese pathos más se evapora el presente y se transforma en un momento efímero entre el pasado y el futuro. Y, por el contrario, en ausencia de ese pathos, el presente tiende a eternizarse y a devorar de igual forma al pasado y al futuro. Tal es nuestra condición actual. Vivimos un tiempo de repetición, y si se acelera esta repetición se produce una sensación que es de vértigo y de estancamiento a la vez. Es tan fácil e irrelevante caer en la ilusión retrospectiva de proyectar el futuro en el pasado como caer en la ilusión prospectiva de proyectar el pasado en el futuro. El presente eterno conforma la equivalencia entre las dos ilusiones y a la vez las neutraliza. Con ello, nuestra condición asume una dimensión kafkiana: lo que existe no tiene explicación, ni por el pasado ni por el futuro. Existe apenas en un mar de indefinición y de contingencia.

Si la modernidad le quita al pasado su capacidad de irrupción y revelación para entregarla al futuro, el presente kafkiano se la quita al futuro. Lo que irrumpe en el presente kafkiano es errático, arbitrario, fortuito y hasta absurdo.

Por el contrario, hay quien observa en la eternización del presente una nueva tempestad del Paraíso que sustenta el Angelus noznus. Según Taylor y Saarinen, "en la red telecomunicacional global de realidades digitalizadas, el espacio parece sucumbir en una presencia que no conoce la ausencia, y el tiempo parece estar condensado en un presente que ni el pasado ni el futuro perturban. Que se llegara a alcanzar el gozo de esa presencia en el presente significaría la cristalización de los sueños más antiguos y más profundos de la imaginación religioso-filosófica occidental" (1994:speed 4). A mi entender, la tempestad digital en las alas del ángel es virtual y puede ser ligada o desligada a voluntad. Es por lo mismo que nuestra condición es mucho menos heroica y promisoria de lo que la tempestad propone. La presencia, cuya posesión es imaginada por la religión y la filosofía, es la fulguración única e irrepetible de una relación sustantiva, producto de una interrogación permanente, sea ésta el acto místico, la superación dialéctica, la realización del Geist, del Selbstsein, el acto existencial o el comunismo. La presencia digital es, por el contrario, la fulguración de una relación de estilo, repetible una y otra vez; una respuesta permanente a todas las posibles interrogantes. Se opone a la historia sin tener la conciencia de que es histórica. Por eso imagina el fin de la historia sin tener que imaginarse su propio fin. 
No es fácil salir de una situación tan convincente en sus contradicciones y ambigüedades, una situación que es tan confortable como intolerable. La eternización del presente implica el fin de las interrogantes permanentes a las que se refiere Merleau-Ponty (1968:50). La época de repetición puede concebirse como progreso y como su contrario. No es posible pensar la transformación social sin el pathos de la tensión entre raíces y opciones, pero tal imposibilidad pierde gran parte de su dramatismo si se juzga que la transformación social, además de impensable, es innecesaria. Esta ambigüedad conduce al apaciguamiento intelectual, que a su vez lleva al conformismo y a la pasividad. Es importante recuperar entonces la capacidad de espanto y que ésta se traduzca en inconformismo y rebeldía. Walter Benjamin, en la primavera de 1940, escribió una advertencia que mantiene su actualidad: "El espanto por el hecho de que las cosas que estamos viviendo [se refiere desde luego al nazismo] 'todavía' sean posibles no es un espanto filosófico. No se sitúa en el umbral de la comprensión, a no ser que se entienda que la concepción de la historia de la cual proviene es insostenible" (1980:697).

En mi opinión, a partir de aquí debemos verificar que la teoría de la historia de la modernidad es insostenible y, por tanto, es necesario sustituirla por otra que nos ayude a vivir con dignidad este momento de peligro y lograr la supervivencia por la profundización de las energías de emancipación. Lo más urgente es contar con una nueva capacidad de espanto y de indignación que sustente una nueva teoría y una nueva práctica de inconformismo, desestabilizadora, es decir, rebelde.

Según la sugerencia de Merleau-Ponty, debemos partir de las significaciones de la modernidad más abiertas y más incompletas. Son éstas los que suscitan la pasión y abren espacios a la creatividad e iniciativa en el ser humano (1968:45). Porque la teoría de la historia de la modernidad se orientó totalmente al futuro, y el pasado quedó subrepresentado y subcodificado. El dilema de nuestro tiempo reside en que a pesar de que el futuro esté desacreditado, aún es posible, en el ámbito de esta teoría, reanimar el pasado. Para la teoría de la historia, el pasado es una acumulación fatalista de catástrofes que el Angelus novus observa de manera impotente y ausente.

Nuestra tarea consiste en reinventar el pasado para que asuma la capacidad de fulguración, irrupción y redención que imaginó Benjamin con clarividencia: "Para el materialismo histórico de lo que se trata es de retener una imagen del pasado tal como ésta aparece ante el sujeto histórico, súbitamente, en el momento de peligro" (1980:695). Esta capacidad de fulguración podrá desarrollarse sólo si el pasado deja de ser la acumulación fatalista de catástrofes para ser tan sólo la anticipación de nuestra indignación y de nuestro inconformismo. El fatalismo es, en la concepción modernista, el otro lado de la confianza en el futuro. El pasado queda así neutralizado en dos niveles: porque sucedió lo que tenía que suceder y porque lo que haya acontecido en un momento dado ya sucedió y puede llegar a superarse con posterioridad. En esta constelación de ilusiones retrospectivas y de ilusiones prospectivas del pasado sólo se aprende a confiar en el futuro. 
Es preciso, pues, luchar por otra concepción del pasado, en la que éste se convierta en razón anticipada de nuestra rabia y de nuestro inconformismo. En vez de un pasado neutralizado, un pasado como pérdida irreparable resultante de iniciativas humanas que pudieron elegir entre alternativas. Un pasado reanimado en nuestra dirección por el sufrimiento y por la opresión que fueron causados por la presencia de alternativas que se podían haber evitado. Es en nombre de una concepción del pasado semejante a éste que Benjamin critica la socialdemocracia alemana. Dice "[La social democracia] se dio el gusto de trasladar a la clase trabajadora el papel de libertadora de las generaciones futuras. Así le cortó el nervio de la mejor fuerza que tenía. En esta escuela, la clase olvidó tanto el odio como el espíritu de sacrificio. Porque éstos se nutren de la imagen de los antepasados esclavizados y no del ideal de los nietos liberados" (1980:700).

Tal vez más que en la época de Benjamin, perdemos la capacidad de enfurecernos y espantarnos frente al realismo grotesco que se acepta sólo porque existe, perdemos la voluntad de sacrificio. Para recuperar una y otra es importante reinventar el pasado como negatividad, producto de la iniciativa humana y, con base en él, construir interrogantes poderosas y adoptar posiciones apasionadas que tengan la capacidad de despertar sentidos fecundos.

Entonces es conveniente identificar el sentido de las interrogantes en un momento de peligro como el que estamos atravesando. Tal identificación se da en dos momentos. El primero es el de la pretendida eficacia a las interrogantes poderosas. Acudo a una expresión un tanto idealista de Merleau-Ponty (1968:44) y pienso que para que las interrogantes poderosas sean eficaces, deben ser monogramas del espíritu sobre las cosas. Deben irrumpir por la intensidad y por la concentración de energía interior que transportan. Tal irrupción, en las condiciones actuales, sólo ocurre si las interrogantes poderosas se traducen en imágenes desestabilizadoras. Son esas imágenes las únicas que pueden restituir la capacidad de espanto y de indignación. En la medida en que el pasado deje de ser automáticamente redimido por el futuro, el sufrimiento humano, la explotación y la opresión que lo habitan se convertirán en un comentario cruel sobre el tiempo presente, inadmisible porque aún sucede y porque la iniciativa del ser humano pudo evitarlo. Las imágenes son desestabilizadoras sólo en la medida en que todo depende de nosotros y todo podría ser diferente y mejor. Así pues, la iniciativa del ser humano, y no cualquier idea abstracta de progreso, puede fundamentar el principio esperanza de Ernst Bloch. El inconformismo es la utopía de la voluntad. Como dice Benjamin, "La chispa de la esperanza sólo posee el don de deslumbrar en el pasado a aquel historiador que está convencido de que ni siquiera los muertos estarán a salvo del enemigo, si éste es el vencedor" (1980:695).

Las imágenes desestabilizadoras serán eficaces sólo si son ampliamente compartidas. Esto me conduce al segundo momento del sentido de las interrogantes poderosas. ¿Como lograr que la interrogante esté más dividida que las respuestas que le fueron dadas? Juzgo que, en el interior de la cultura occidental, en el momento actual de peligro, la interrogante poderosa, para ser ampliamente dividida, debe incidir más 
sobre lo que nos une que sobre lo que nos separa. Porque uno de los ardides de la ecuación raíces/opciones fue ocultar, bajo la capa del equilibrio entre una y otra, el predominio total de las opciones, por lo cual tenemos en la actualidad múltiples teorías y prácticas de separación y de varios grados de separación. Por el contario, carecemos de teorías de unión, y esta carencia resulta grave en extremo en un momento de peligro. La gravedad de tal carencia no está en sí misma, sino en el hecho de coexistir con una plétora de teorías de la separación. Lo más grave es el desequilibrio entre las teorías de la separación y las teorías de la unión.

Los poderes hegemónicos que rigen la sociedad de consumo y la sociedad de información han promovido teorías e imágenes que apelan a una totalidad -sea ésta de la especie, del mundo y hasta del universo-, que existe por encima de las divisiones entre las partes que la componen. Sabemos que se trata de teorías e imágenes manipuladoras que ignoran las diversas circunstancias y aspiraciones de los pueblos, clases, sexos, regiones, etc., así como las relaciones de desigualdad, explotación y victimación que han unido las partes que componen esa seudototalidad. Sin embargo, el grado de credibilidad de esas teorías e imágenes consiste en apelar, aunque de manera manipulatoria, a una comunidad imaginada de la humanidad en su conjunto. La CNN, en contra de las teorías de la separación, descubrió un universalismo a posteriori si-multáneamente global e individual, la universalidad y la individualidad del sufrimiento: el sufrimiento ocurre en todas partes; los individuos son los que sufren, no las sociedades.

A su vez, las fuerzas contrahegemónicas han contribuido a ampliar las arenas de entendimiento político; pero, en general, las coaliciones y las alianzas han sido poco eficaces para superar las teorías de la separación, aunque han sido más eficaces para superar las separaciones territoriales de lo que han podido superar las separaciones que provocan las diferentes formas de discriminación y opresión. Las coaliciones transnacionales han sido más fáciles entre grupos feministas y entre ecologistas o indígenas que entre unos y otros grupos. Esto se debe al desequilibrio entre las teorías de la separación y las de unión. Estas últimas, entonces, deben reforzarse para que se vuelva visible lo que hay de común entre las diferentes formas de discriminación y de opresión: el sufrimiento humano.

La globalización contrahegemónica, que yo he designado "cosmopolitismo", está inserta en el carácter global y multidimensional del sufrimiento humano. La idea del totus orbis, formulada por Francisco de Vitoria, uno de los fundadores del derecho internacional moderno, debe ser reconstituida como globalización contrahegemónica, como cosmopolitismo. El respeto por la diferencia no puede impedir la comunicación y complicidad que hace posible la lucha contra la indiferencia. El momento de peligro por el que estamos atravesando exige que profundicemos en la comunicación y la complicidad. Debemos hacerlo, no en nombre de una communitas abstracta, sino movidos por la imagen desestabilizadora del sufrimiento multiforme causado por la iniciativa humana, tan avasallador como innecesario. Las teorías de la separación, en este momento de peligro, deben formularse sin perder de vista lo que nos une; y viceversa, las teorías de la unión deben formularse tomando en cuenta 
lo que nos divide. Las fronteras divisorias deben construirse con numerosas entradas y salidas. Al mismo tiempo, es importante mantener en mente que lo que une sólo une a posteriori.

La comunicación y la complicidad deben darse con apoyo y en varios niveles para que haya un equilibrio dinámico entre las teorías de la separación y las teorías de la unión. A cada nivel le corresponde un potencial de indignación e inconformismo, alimentado por una imagen desestabilizadora. Propongo que distingamos cuatro niveles: el epistemológico, el metodológico, el político y el jurídico.

La comunicación y la complicidad epistemológicas se asientan en la idea de que no existe sólo una forma de conocimiento, sino varias, y que es preciso optar por la que favorece la creación de imágenes desestabilizadoras y una actitud de inconformismo frente a ellas. Yo defiendo la posición de que no hay conocimiento en general ni ignorancia en general. Cada forma de conocimiento conoce en relación a un cierto tipo de ignoracia y viceversa, cada forma de ignorancia es ignorancia de un cierto tipo de conocimiento. Cada forma de conocimiento implica así una trayectoria de un punto A, designado por la ignorancia, a un punto B, designado por el saber. Las formas de conocimiento se distinguen por el modo en que caracterizan los dos puntos y las trayectorias entre ellos. Esta trayectoria, en la modernidad de Occidente, es, simultáneamente, una secuencia lógica y una secuencia temporal. El movimiento de la ignorancia al saber es también el movimiento del pasado al futuro.

Defiendo que el paradigma de la modernidad contiene dos formas importantes de conocimiento: conocimiento-regulación y conocimiento-emancipación (1995:25). El conocimiento-regulación consiste en una trayectoria entre un punto de ignorancia, denominado caos, y un punto de conocimiento, denominado orden. El conocimiento-emancipación consiste en una trayectoria entre un punto de ignorancia, denominado colonialismo, y un punto de conocimiento, denominado solidaridad. Si bien estas dos formas de conocimiento están igualmente inscritas en el paradigma de la modernidad, el conocimiento-regulación, durante el último siglo, ha ganado primacía total sobre el conocimiento-emancipación. El orden, con esto, pasó a ser la forma hegemónica del conocimiento, y el caos, la forma hegemónica de la ignorancia. Dicha hegemonía del conocimiento-regulación le permitió recodificar el conocimiento-emancipación en sus propios términos. Así, lo que era saber en esta última forma de conocimiento, se transformó en ignorancia (la solidaridad se convirtió en caos) y lo que era ignorancia se transformó en saber (el colonialismo fue recodificado como orden). Como la secuencia lógica de la ignorancia al saber es también la secuencia temporal del pasado al futuro, la hegemonía del conocimiento-regulación hizo que tanto el futuro como la transformación social se concibieran como orden, y el colonialismo, como un tipo de orden. De forma paralela, el pasado se concibió como el caos, y la solidaridad como un tipo de caos. El sufrimiento humano puede justificarse así en nombre de la lucha del orden y del colonialismo contra el caos y la solidaridad. Ese sufrimiento humano tuvo, y sigue teniendo, destinatarios sociales específicos - trabajadores, mujeres, minorías étnicas y sexuales-, cada uno de los cuales es considerado peligroso a su modo porque representa el caos y la 
solidaridad contra quienes es preciso luchar en nombre del orden y del colonialismo. La neutralización epistemológica del pasado siempre ha sido la contraparte de la neutralización social y política de las "clases peligrosas".

Frente a esto, la orientación epistemológica que hace posible la comunicación y la complicidad debe revalorar a la solidaridad como forma de conocimiento y al caos como una dimensión de la solidaridad. En otras palabras, debe pasar por la revalorización del conocimiento-emancipación en detrimento del conocimiento-regulación. La imagen desestabilizadora que generará la energía de esta revalorización es el sufrimiento humano, concebido como el resultado de toda iniciativa humana que convierta la solidaridad en forma de ignorancia y el colonialismo en forma de saber.

La segunda orientación es metodológica. Las teorías sobre lo que nos une, propuestas por la sociedad de consumo y por la sociedad de información, se asientan en la idea de globalización. Las globalizaciones hegemónicas son, de hecho, localismos globalizados, los nuevos imperialismos culturales. Podemos definir la globalización hegemónica como el proceso por el cual un fenómeno dado o entidad local consigue difundirse globalmente y, al lograrlo, adquiere la capacidad de designar a un fenómeno o a una entidad rival como local. La comunicación y la complicidad que permite la globalización hegemónica se asientan en un intercambio desigual que canibaliza las diferencias en vez de permitir el diálogo entre ellas. Están bajo la insidia de silencios, manipulaciones y exclusiones.

En contra de los localismos globalizados propongo, como orientación metodológica, la hermenéutica diatópica. ${ }^{4}$ Se trata de un procedimiento hermenéutico cuya base radica en la idea de que todas las culturas están incompletas y de que los topoi de una cultura determinada, por más fuertes que sean, están tan incompletos como la cultura a la que pertenecen. Los topoi fuertes son las principales premisas de argumentación dentro de una cultura determinada, las premisas que hacen posible la creación de argumentos y su intercambio. Esta función de los topoi genera una ilusión de totalidad con base en la inducción pars pro toto. Por eso, la incompletud de una cultura determinada sólo puede validarse a partir de los topoi de otra cultura. Los topoi de una cultura determinada, vistos desde otra cultura, dejan de ser premisas de argumentación para convertirse en meros argumentos. ${ }^{5} \mathrm{El}$ objetivo de la hermenéutica diatópica es el de llevar al máximo la conciencia de la incompletud recíproca de las culturas a través del diálogo con un pie en una cultura y el otro pie en la otra. De ahí su carácter diatópico. La hermenéutica diatópica es un ejercicio de reciprocidad entre culturas que consiste en transformar las premisas de argumenta-

\footnotetext{
${ }^{4}$ El concepto de hermenéutica diatópica lo desarrollo en otro trabajo con mayor detalle (Santos, 1995:337-347).

${ }^{5}$ En momentos de gran turbulencia, en el pasaje "descendente" de los topoi de las premisas de la argumentación, la simple argumentación puede hacerse visible desde dentro de una cultura determinada. De algún modo, es lo que puede ocurrir con la ecuación entre ráces y opciones. En la narración que propongo en este texto, cuestiono tal ecuación como un topos fuerte de la cultura eurocéntrica y, al hacerlo, "la derrito" de premisas de argumentación y la convierto en simple argumento, la refuto con otros argumentos.
} 
ción de una cultura determinada en argumentos inteligibles y creíbles en otra cultura. Para dar un ejemplo, en otros trabajos (1995:337-347) he propuesto una hermenéutica diatópica entre el topos de los derechos humanos de la cultura occidental y el topos de la darma en la cultura hindú; y entre el topos de los derechos humanos y el topos de la umma en la cultura islámica, en este caso, en diálogo con Abdullahi Ahmed An-na'im (1990; 1992).

Elevar la incompletud al máximo de conciencia posible abre posibilidades insospechadas a la comunicación y a la complicidad. Se trata de un procedimiento difícil, postcolonial y postimperial y, en cierto sentido, más allá de la identidad. La propia reflexión sobre las condiciones que la vuelven posible y necesaria es una de las condiciones más exigentes de la hermenéutica diatópica. La energía que la pone en práctica, con un fuerte contenido utópico, proviene de una imagen desestabilizadora que he designado epistemicidio, el asesinato del conocimiento. Los intercambios desiguales entre culturas siempre han acarreado la muerte del conocimiento propio de la cultura subordinada y, por lo mismo, de los grupos sociales que la practican. En los casos más extremos, como el de la exclusión europea, el epistemicidio fue una de las condiciones del genocidio. La pérdida de confianza epistemológica por la que atraviesa la ciencia moderna logra identificar el ámbito y la gravedad de los epistemicidios cometidos por la modernidad hegemónica eurocéntrica. La imagen de tales epistemicidios será más desestabilizadora cuanto más consistencia tenga la práctica de la hermenéutica diatópica.

La tercera orientación para lograr un equilibrio dinámico entre las teorías de la separación y las teorías de la unión es política, y la he designado, siguiendo a Richard Falk, "gobierno humano" (human governance). Las teorías hegemónicas de la unión, comenzando por la economía de mercado y por la democracia liberal, están generando formas de barbarie, de exclusión y de destitución que redundan en prácticas de neofeudalismo. A su vez, las teorías contrahegemónicas de separación, como por ejemplo las que subyacen en muchas políticas de identidad, han redundado en ciertas ocasiones en prácticas fundamentalistas o neotribales porque no cuentan con el contrapeso de las teorías de la unión.

Es por estas dos vías opuestas, pero convergentes en sí, que estamos viviendo una época de exceso de separatismo y de segregacionismo. Es necesario construir una imagen desestabilizadora, la imagen del apartheid global, un mundo de guetos sin entrada ni salida, que anda errante en un mar de corrientes colonialistas y fascistas. Esta imagen desestabilizadora constituirá la energía de la orientación política del gobierno humano. En la estela de Falk, lo entiendo como todo criterio normativo que "facilite la comunicación a través de divisiones de civilización, nacionalistas, étnicas, clasistas, generacionales, cognitivas y sexuales", pero que lo hace con "respeto y celebración de la diferencia y una actitud de extremo escepticismo para con los sobresaltos exclusivistas que niegan los espacios de expresión y descubrimiento de los otros, así como para las variantes del universalismo que ignoran las circunstancias desiguales y las aspiraciones de los pueblos, clases y regiones" (1995:242). En otras palabras, el gobierno humano es un proyecto normativo que, "en todos y en cual- 
quier contexto, identifica y restablece constantemente las diversas interfases entre lo específico y lo general, y mantiene sus fronteras mentales y espaciales abiertas como entradas y salidas, aunque sigue desconfiando de cualquier versión de pretensión de verdad en cuanto fundamento para el extremismo y la violencia política" (1995:242). El principio de gobierno humano, impulsado por una imagen desestabilizadora - el apartheid global- poderosa porque está asociada a la guerra, a las desigualdades abismales y al colapso ecológico, tiene un potencial de oposición muy elevado. Tal vez, más que las orientaciones restantes, tiene un carácter eurocéntrico por su aspiración de totalidad. Representa, así, el máximo de conciencia centrífuga del eurocentrismo al comprometerse con sus víctimas y al aspirar a una totalidad emancipatoria que tenga como centro el sufrimiento de las víctimas.

Para terminar, la orientación jurídica para el momento de peligro que estamos atravesando proviene del derecho internacional. Se trata de la doctrina "patrimonio común de la humanidad" (common heritage of humankind), sin duda la doctrina sustantiva más innovadora, también la más vilipendiada, del derecho internacional en la segunda mitad del siglo Xx. La existencia de campos sociales, físicos o simbólicos, que son res communis y que sólo pueden ser administrados en interés de la comunidad, es una condición sine qua non de la comunicación y complicidad entre la parte y el todo que aquí se sustenta con el objeto de lograr un mayor equilibrio entre las teorías de la separación y las teorías de la unión. Si el todo, sea éste la especie, el mundo o el universo, no tiene un espacio jurídico propio, quedará sujeto a los dos criterios básicos de separación de la modernidad: la propiedad, en la que se asienta el capitalismo mundial, y la soberanía, en la que se asienta el sistema interestatal. El monopolio jurídico detentado por estos dos criterios ha destruido, o ha amenazado destruir, recursos naturales y culturales de importancia vital para la sustentabilidad y calidad de vida en la Tierra. El fondo marino, la Antártida, la Luna y otros cuerpos celestes, el espacio exterior, el ambiente global, la biodiversidad ${ }^{\natural}$ son algunos de los recursos que, si no son administrados por trustees de la comunidad internacional en favor de las generaciones presentes y futuras, sufrirán un desgaste tal que la vida en la Tierra se hará intolerable hasta dentro de los guetos de lujo que componen el apartheid global. La imagen desestabilizadora que surge de aquí es la parábola de la tragedia de los comunes enunciada por Garrett Hardin (1968). ${ }^{7}$ Como los costos del uso individual de los bienes comunes son siempre inferiores a su beneficio, los recursos comunes, al ser agotables, se encuentran irremediablemente al borde de una tragedia. Esta imagen será más desestabilizadora cuanto más elevada sea la conciencia

${ }^{\circ}$ La UNESCO también considera el patrimonio cultural como patrimonio común de la humanidad. En este caso, y desde mi perspectiva, es el mismo patrimonio, y no su degradación, el que debe constituir una imagen desestabilizadora: imagen de las condiciones de barbarie en que se produjeron los tesoros culturales. El patrimonio, por ello, sólo puede ser considerado patrimonio común de la humanidad si se observa desde la perspectiva de Benjamin cuando afirma: "No hay documento de la cultura que no sea, al mismo tiempo, un documento de la barbarie" (1980:696).

${ }^{7}$ Un análisis importante de esta parábola puede leerse en Pureza (1995:281). 
ecológica global. Y es ésta la que genera la energía de la orientación del patrimonio común de la humanidad. No cabe aquí analizar esta doctrina que se formuló por primera vez en 1967; ni la Convención de las Naciones Unidas sobre el Derecho del Mar en 1982, cuando fue posible observar la aspiración de los países periféricos a un nuevo orden económico mundial; ni la progresiva desvirtuación de esa doctrina hasta llegar al colapso total en el Boat Papery en la Resolución 48/263 de la Asamblea General de las Naciones Unidas el 28 de julio de 1998 (Santos, 1995:365-373; Pureza, 1995). ${ }^{8}$

La dimensión arquetípica del patrimonio común de la humanidad reside en que, mucho antes de haber sido formulada expresamente, esta idea representa la dialéctica de la comunicación entre las partes y el todo que estuvo en el origen del derecho internacional moderno en la Escuela Ibérica del siglo XVI (Pureza, 1995:264). La distinción de Francisco de Vitoria entre el jus inter omnes gentes y el totus orbis, y la distinción de Francisco Suárez entre el jus gentium inter gentes y el bonnun commune humanitates son los arquetipos del equilibrio matricial entre las teorías de la separación y las teorías de la unión. El hecho de que se haya perdido este equilibrio en favor de las teorías de la separación confiere a la doctrina del patrimonio común de la humanidad un carácter utópico, mesiánico en el sentido de Benjamin. Baste enumerar sus atributos principales: "no apropiación; gestión de todos los pueblos; repartición internacional de los beneficios obtenidos por la explotación de recursos naturales; utilización pacífica de la investigación científica para beneficio de todos los pueblos, incluida la libertad; conservación para las generaciones futuras" (Santos, 1995:366). Para que este carácter utópico se desarrolle, es necesario que la idea del patrimonio común de la humanidad salga del discurso y las prácticas jurídicas del derecho internacional - donde siempre será amagado por los principios de propiedad y de soberanía-, y se transforme en un nuevo sentido común jurídico emancipatorio que alimente la acción de los movimien tos sociales contrahegemónicos y de las organizaciones no gubernamentales de advocacy transnacional.

\section{CONCLUSIÓN}

Estamos pasando por un momento de peligro que también es un momento de transición. El futuro ya perdió su capacidad de redención y de fulguración, y el pasado aún no la ha adquirido. Ya no somos capaces de pensar la transformación social en términos de la ecuación raíces y opciones, pero tampoco somos capaces de pensar sin ella. $\mathrm{El}$ peligro radica en que se eternice el presente y en su capacidad de fulguración kafkiana; en que, una vez desprovistos de las tensiones en que conformamos nuestra subjetividad, nos quedemos con formas simplificadas de subjetividad.

\footnotetext{
${ }^{8}$ Para un análisis detallado y crítico de las vicisitudes de la doctrina del patrimonio común de la humanidad, of. Pureza (1995:381-531).
} 
Uno de los síntomas más pertubadores de la subjetividad simplificada es el hecho de que las teorías de la separación y la segregación lleguen a dominar totalmente a las teorías de la unión, de la comunicación y de la complicidad. La irrelevancia de la ecuación raíces/opciones reside precisamente en el hecho de que estamos segregados y separados, tanto por las raíces como por las opciones. Por ello, las razones limitadas que invocamos para las segregaciones, tanto hegemónicas como contrahegemónicas, no explican los límites de la segregación.

En este texto propuse un nuevo equilibrio entre las teorías de la separación y las teorías de la unión, una mayor comunicación y complicidad a través de las fronteras. Propuse cuatro imágenes desestabilizadoras -el sufrimiento humano, el epistemicidio, el apartheid global y la tragedia de los comunes-que interpelan todas ellas al pasado como iniciativa humana inadmisible, y permiten que éste se reavive y brille en nuestra dirección. Estas imágenes son eso, imágenes. No son ideas, porque las ideas perdieron toda capacidad de desestabilización. Se trata de nuevas constelaciones donde se combinan ideas, emociones, sentimientos de espanto y de indignación, pasiones de sentidos inagotables. Son monogramas del espiritu puestos a la disposición de nuevas prácticas rebeldes e inconformistas.

Sólo bajo estas condiciones las imágenes desestabilizadoras generarán la energía que logre observar las cuatro orientaciones que nos permitan sobrevivir con dignidad este momento de peligro - el conocimiento-emanicpación, la hermenéutica diatópica, el gobierno humano y el patrimonio común de la humanidad. Son orientaciones en los márgenes de la cultura eurocéntrica, pero aun así, eurocéntricas en su marginalidad. Como se colocan del lado de las víctimas de la hegemonía del eurocentrismo, se constituyen en conciencia de oposición y centrífuga, el máximo posible de conciencia de la incompletud de la cultura occidental. Piensan la cultura occidental para que la transformación social deje de ser pensada en términos eurocéntricos.

Es por esta razón que el Angelus novus no puede continuar, suspendido de su imponderable levedad, dando la espalda a quien causa tảles horrores. Si ello sucede, la tragedia del ángel se convertirá en una farsa, en una interrogante poderosa, en comentario patético. Por el contrario, pienso que frente a la intensidad seductora y monstruosa de las imágenes desestabilizadoras, el ángel terminará por sumergirse en ellas y así obtener la energía necesaria para volar de nuevo, esta vez con prudencia, es decir, con los pies en la tierra. Sólo así el ángel despertará a los muertos y reunirá a los vencidos. 
BIBLIOGRAFIA

An-na'im, Abdullahi A., 1990, Toward an Islamic Reformation, Syracuse University Press, Siracusa.

An-na'im, Abdullahi A. (comp.), 1992, Human Rights in Cross-Cultural Perspectives. A Quest for Consensus, University of Pennsylvania Press, Filadelfia.

Benjamin, Walter, 1980, "Über den Begriff der Geschichte", en W. B., Gesammelte Schriften. Werkausgabe, Suhrkamp, Frankfurt del Main, vol. 2, pp. 693-704.

Bernal, Martin, 1987, Black Athena: The Afroasiatic Roots of Classical Civilization, vol. 1, The Fabrication of Ancient Greece, 1785-1885, Free Association Books, Londres.

Bloom, Harold, 1994, The Western Canon: The Books and Schools of the Ages, Harcourt, Nueva York.

Comesaña, Gloria, 1993, "Walter Benjamin: la historia entre teología y revolución", Revisia de Filosofia, Universidad de Zulia, Maracaibo, 16/17:91-108.

Deleuze, Gilles, 1968, Différence et Répétition, Presses Universitaires de France, París.

Falk, Richard, 1995, On Human Governance: Toward a New Global Politics, The Pennsylvania State University Press, University Park, Pensilvania.

Gilroy, Paul, 1993, The Black Atlantic. Modernity and Double Consciousness, Harvard University Press, Cambridge.

Gordon, Linda, 1990, Woman's Body, Woman's Right. Birth Control in America, ed. corregida y aumentada, Penguin, Nueva York.

Gordon, Linda (comp.), 1991, Women, the State and Welfare, The University of Wisconsin Press, Madison.

Grotius, Hugo, 1964, De Jure Belli ac Pacis Libri Tres, vol. II, Oceana Publications, Nueva York.

Haraway, Donna, 1989, Primate Visions, Routledge, Nueva York.

Hardin Garret, 1968, "The Tragedy of the Commons", Science, 162.

Homans, Peter, 1993, Jung in Context, 2a. ed., University of Chicago Press, Chicago.

Huntington, Samuel, 1993, "The Glash of Civilizations?", Foreign Affairs, vol. 72, núm. 3.

Merleau-Ponty, Marcel, 1968, Résumés de cours. Collège de France 1952-1960, Gallimard, París.

Prigogine I. e I. Stengers, 1979, La Nouvelle Alliance: Metamorphose de la Science, Gallimard, París.

Prigogine, I., 1980, From Being to Becoming, Freeeman, San Francisco. 
Pureza, José Manuel, 1995, O Patrimonio Comùm da Humanidade: Rumo a um Dereito Internacional da Solidaridade? Facultade de Economia da Universidade de Coimbra, Coimbra.

Ribeiro, António Sousa, 1995, "Walter Benjamin, Pensador da Modernidade", Oficinas do CES, 41.

Rousseau, Jean Jacques, 1989, O Contrato Social, $3^{\underline{a}}$ ed., Publicações Europa-América, Mem Martins.

Santos, Boaventura de Sousa, 1995, Toward a New Common Sense: Law, Science and Politics in the Paradigmatic Transition, Routledge, Nueva York.

Taylor, Mark y Esa Saarinen, 1994, Imagologies: Media Philosophy, Routledge, Nueva York.

Tuck, Richard, 1979, Natural Rights Theories: Their Origin and Development, Cambridge University Press, Cambridge.

Van der Abbeele, Georges, 1992, Travel as Metaphor, University of Minnesota Press, Minneapolis.

Vico, Giambattista, 1961, The New Science of Gianmbattista Vico, editado por Bergin y Fisch, Anchor Books, Garden City, Nueva York. 